Thus the entire field of monosaccharide chemistry is covered. I thoroughly enjoyed reading the book and was particularly impressed by Chapters $2,4,6,12,15,18,20$, 31,35 and 36 . The standard of treatment is uniformly high: reaction mechanisms are given where appropriate and a comprehensive bibliography (including references to the patent literature) is given at the end of each chapter. It is noted that recrystallization of some monosaccharides from boiling solvents may lead to traces of new substances, for example, D-fructose from ethanol.

There can be little doubt that Dr. Staněk's book will be regarded as the standard reference work on the monosaccharides and no carbohydrate chemist can afford to be without it either in his personal library or in his laboratory. I suggest that all libraries should acquire a copy: most organic chemists will wish to own or have access to this excellent book. The price is high, but not unduly so by modern standards having regard to its length and content.

The translation is generally good, but a few isolated clumsy expressions will be found (see, for example, pp. 35, 37, 117, 539): only two misprints were found (pp. 563 and 869). The author and subject indexes are very satisfactory. The book was printed in Czechoslovakia: the production and format are very creditable by any criteria.

A. I. VOGEL

\section{PEROXIDASE AND RELATED CATALYSTS}

\section{Peroxidase}

The Properties and Uses of a Versatile Enzyme and of some Related Catalysts. By Dr. B. G. Saunders, Dr. A. G. Holmes-Siedle and Dr. B. P. Stark. Pp. $x+271$. (London: Butterworth and Co. (Publishers), Ltd., 1964.) $60 s$.

CINCE the publication in 1948 of Lemberg and Legge's $\$$ comprehensive Hematin Compounds and Bile Pig. ments no comparable survey of so vast a field has appeared. This is scarcely surprising in view of the explosive growth of knowledge since that time. The present volume, dealing with one group of haemoproteins, is an inevitablo development. It provides very broad cover: it deals with sources of enzyme, isolation and purification, chemical and physical properties, spectroscopy and reaction kinetics, possible biological roles, and the chemistry of oxidation products of hydrogen donors in peroxidatic reactions. There is also a chapter on "Contributions to the Problem from Inorganic Chemistry" and an extremely useful atlas of haemoprotein spectra. The sequence of subject-matter does not follow a very logical course: thus a complete account of the Chance mechanism for the reaction of horse-radish peroxidase with peroxides is scattered in four chapters: under general survey, properties of peroxidase, rapid reaction mechanisms and chemistry of peroxide compounds. Other subjects, such as George's concept of higher oxidation states of iron, are similarly fragmented. Although Chapter 8 is entitled "The Spectra and Function of the Haemoproteins", questions of biological function are first considered in Chapter 9. However, a very full index enables such difficulties to be surmounted.

The authors write in two very distinct styles: (1) comprehensive reporting of the literature, devoid of critical evaluation and often highly compressed; (2) authoritative summaries of certain fields to which the authors have themselves made valuable contributions. While it is inevitable that some emphasis of the authors' interests should occur, the imbalance can become excessive as in the introductory chapter "General Survey" in which 28 out of 37 pages are occupied by an account-and an excellent one - of the authors' work on the peroxidation products of phenols and aromatic amines.

The enzyme peroxidase is widely distributed in plants, but many references to animal peroxidases must bo treated with reserve since all haemoproteins, and other haematin derivatives, can catalyse reactions which, at least superficially, are similar to those that characterize peroxidase. However, the activity of such derivatives is lower, by a factor of at least 10,000, than that of the enzyme peroxidase and is at the level of denatured peroxidase. Failure to appreciate this point has been frequent and it is unfortunate that the authors of this book have not driven the point home. They define true, atypical, artificial and model peroxidases and state that, failing indication to the contrary, the term peroxidase will be used to mean true peroxidase, that is, a haemoprotein enzyme. In Chapter 13, however, they make the surprising statement that "most workers agree that true peroxidase activity seems to be largely restricted to iron-porphyrin compounds and to iron phthalocyanines". They then ascribe peroxidase activity to such diverse materials as heavy motal compounds, granite, charcoal, aldehydes, organophosphorus compounds, nucleic acids and vitamin $A$. Traces of heavy metals can accelerate the peroxidation of typical hydrogen donors for peroxidase, and the list of materials with thermostable peroxidase-like activity can be extended indefinitely (to include even the dust on the laboratory floor) so long as no standard criteria of reaction rates or specific activities are applied.

Chapter 9, on catalase, gives emphasis to the peroxidatic activity of the enzyme. Under "Biological Role" (and again, for no obvious reason, in Chapter 13) are described. in vitro reactions which the enzyme is known to catalyse. However, we do not know whether such reactions are related to its biological function. A more serious error is the statement, made more than once, that in the functioning of the respiratory chain cytochrome reduces oxygen to hydrogen peroxide and, by inference, that the decomposition of such peroxide is a biological role of catalase. The brief comments (p. 91) on the use of the spectroscope by MacMunn and by Keilin are quite inaccurate and the statement that cytochrome $c$ peroxidase is associated with the respiratory chain will be disputed. Otherwise errors of fact are very few. It is not clear why almost identical tables appear on pages 35 and 147 , and the thirteen pages occupied by structural formulae in Appendix $A$ might have been put to better use since most of the formulae appear in Chapter 1.

The authors no doubt felt that considerations of non-enzymatic peroxidation would widen the interest in their book. But to those whose attention is caught by the title, to the enzymologist, these considerations will be seen as intrusions on limited space. While this book contains snares for the nowcomer there is no doubt that it will become an essential work of reference for all who wish to keep abreast with developments in haemoprotein catalysis.

E. F. Hartree

\section{POSITRONIUM-THE CHEMISTRY OF A MINIATURE HYDROGEN}

\section{Positronium Chemistry}

By James Green and John Lee. Pp. xii + 105. (New York: Academic Books, Inc.; London: Academic Books, Ino. (London), Ltd., 1964.) $44 s$.

$\mathrm{D}$ ESPITF the short history of positronium chemistry and the comparatively few workers actively involved, there is a great amount of recorded data, as is evidenced by the extensive and thorough bibliography provided in this book. The authors have obviously decided to cope with this situation by selecting certain aspects which interest them most. Most readers, however, will require to be 'put in the picture' and this is attempted in an opening chapter of eight pages. This is condensation at its worst and the result is most unsatisfactory. The authors hop 